ARTÍCULO ORIGINAL

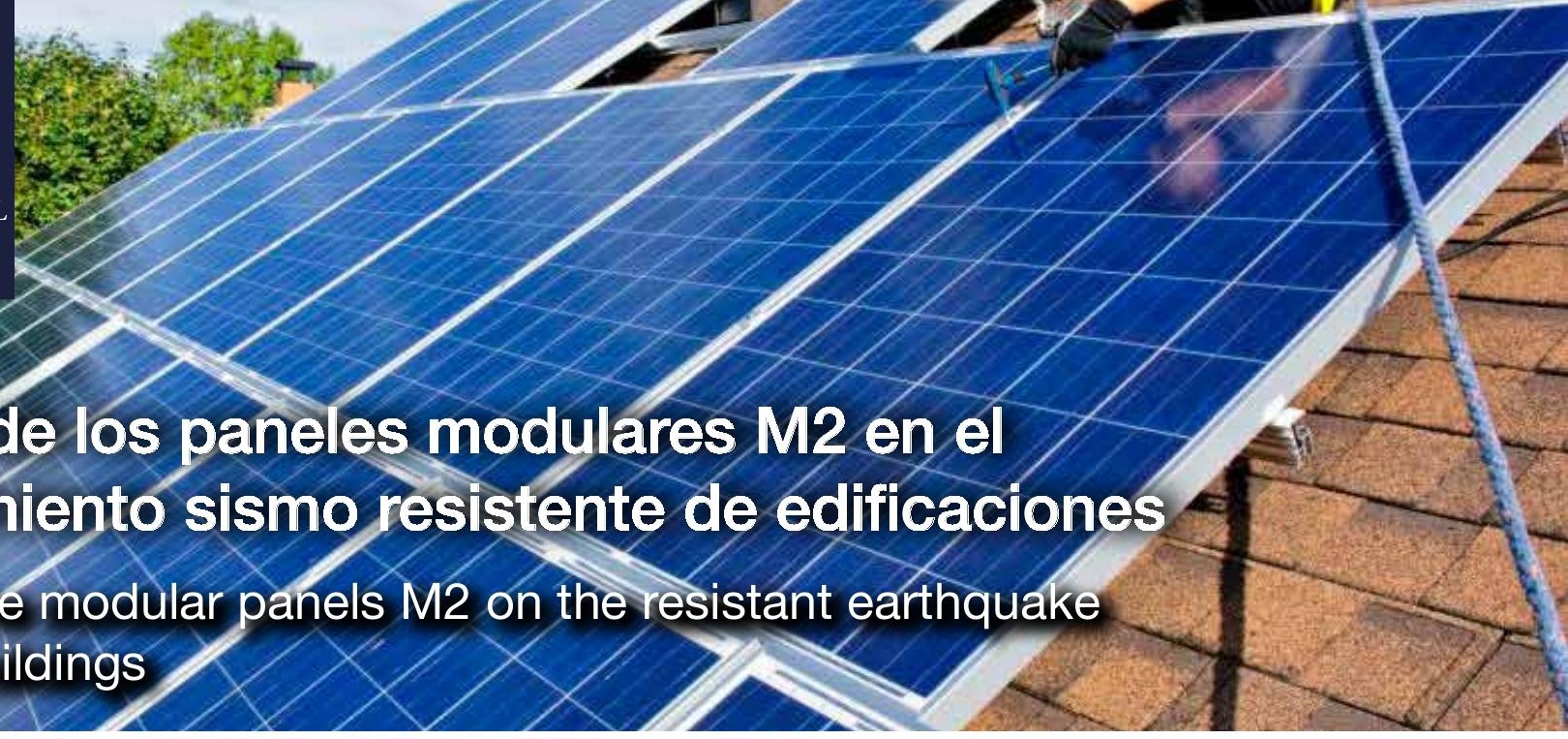

\title{
behavior of buildings
}

DOI: https://doi.org/10.29166/revfig.vli2.1609

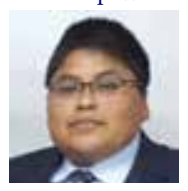

\section{Morales Luis}

Magister en Estructuras y Ciencias de los Materiales, docente titular Facultad de Ingeniería, Ciencias Físicas y Matemática de la UCE

Email: Iwmorales@uce.edu.ec

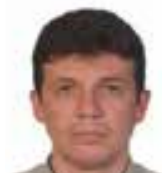

Santamaría Jorge

$\mathrm{PhD}$ en Ingeniería, docente titular Facultad de Ingeniería, Ciencias Físicas y Matemática de la UCE Email: jsantamaria@uce.edu.ec

\section{Resumen}

La investigación consiste en analizar la influencia de los paneles modulares M2 en el comportamiento sismo resistente de edificaciones. En un $1^{\circ}$ Caso: se consideró al panel M2 como mampostería confinada y en un $2^{\circ}$ Caso: como sistemas de pisos (losas). Para ello se consideraron 5 proyectos arquitectónicos diferentes ubicados en Quito. Una vez que los sistemas aporticados planteados alcancen los parámetros sismo resistentes establecidos en la normativa, en un $1^{\circ}$ Caso, se incorporan, los paneles modulares M2 como mampostería confinada en edificios de 3, 6 y 9 pisos. Mientras que, en un $2^{\circ}$ Caso, se dispuso que el panel modular M2 sea considerado como sistema de piso (losas). De estos dos grupos de edificaciones con diferente disposición de los paneles, se determinan nuevos valores de respuestas estructurales, con cuyos datos se procede a comparar con los resultados obtenidos con el sistema aporticado. Para la colocación de los paneles modulares como mampostería, dentro de los sistemas estructurales propuestos, se utilizó el método puntal equivalente, donde las paredes trabajan sólo axialmente a compresión y no absorben cortante. Mientras que, para los sistemas de pisos, se utilizó como modelo base, al sistema de piso con stell deck y otra con la implementación de paneles modulares M2. Para ello se dispuso de dos edificios de mediana altura (6 pisos) y gran altura (16 pisos). Del análisis estructural, para ambos casos: los sistemas aporticados con paneles modulares M2, utilizados tanto como mampostería confinada como sistemas de piso (losas), generó respuestas estructurales como períodos y derivas de piso menores que el sistema sólo aporticado, debido a que el panel modular M2 aporta rigidez lateral y disminuye el peso de las edificaciones, demostrando así que: se puede reducir la vulnerabilidad estructural y mejorar el comportamiento estructural de edificaciones, ante la acción sísmica.

Palabras Claves: hormigón; paneles modulares m2; sistemas de piso, mampostería confinada; análisis sismo resistente; respuestas estructurales.

\section{Abstract}

The investigation consists of analyzing the influence of the modular panels M2 on the resistant earthquake behavior of buildings. In a 1st case: the M2 panel was considered as confined masonry and in a 2nd case: as floor systems (slabs). For this purpose, 5 different architectural projects located in Quito were used. Once the proposed systems have reached the earthquake resistant parameters established in the regulations, in a 1st case, the M2 modular panels are incorporated as confined masonry in buildings of 3, 6 and 9 floors. While, in a 2nd case, it was arranged that the modular panel M2 be considered as a floor system (slabs). Of these two groups of buildings with different layout of the panels, new values of structural responses are determined, with whose data we proceed to compare with the results obtained with the contributed system. For the placement of the modular panels as masonry within the proposed structural systems, the equivalent strut method was used, where the walls work only axially under compression and do not absorb shear. While, for floor systems, the floor system with stell deck was used as a base model and another with the implementation of modular M2 panels. For this, two buildings of medium height (6 floors) and high height (16 floors) were available. From the structural analysis, for both cases: the systems contributed with modular M2 panels used both as confined masonry and floor systems (slabs), generated structural responses as periods and floor drifts lower than the system only contributed, because the modular panel M2 provides lateral stiffness and decreases the weight of the buildings, demonstrating that: structural vulnerability can be reduced and the structural behavior of.

Keywords: concrete; modular panels m2; floor systems; confined masonry; earthquake resistant analysis; structural responses. 


\section{Introducción}

Nuestro país es vulnerable ante catástrofes naturales como el sismo, ocasionados por 3 fenómenos: el de subducción, fallas locales y los terremotos relacionados con la actividad volcánica.

La ciudad de Quito, en particular, puede ser afectada en gran magnitud por sismos que tienen sus orígenes por la presencia de las fallas activas locales, que podrían ocasionar movimientos constantes y tendrían gran potencial para generar sismos destructivos. Por otra parte, el desarrollo de la ciudad es en sentido vertical, mediante la construcción de grandes edificios, los mismos que deberán ser diseñados en base a estudios que aporten a reducir la vulnerabilidad sísmica y, mejorar el comportamiento global de las estructuras ante la acción de cargas laterales y gravitacionales.

Por otra parte, los sistemas constructivos en edificaciones, se han mantenido por décadas volviéndose convencionales, siendo necesario ya un cambio, esto debido a la necesidad que tiene nuestro país por la zona geográfica en donde se encuentra y los peligros a los que está expuesto, para lo que se necesitan estructuras que brinden mayor seguridad a la población; en los últimos años ha aumentado la aplicación de nuevos métodos constructivos, aplicados a diferentes elementos estructurales, como es la prefabricación de elementos. La losa, así como la mampostería son los elementos estructurales donde se ha evidenciado mayor crecimiento innovador, saliendo al mercado nuevos tipos de losas y mamposterías como las conformadas por placas cooperantes, aquellas formadas o construidas por paneles de poliestireno, conocida como panel modular M2 y planchas de fibrocemento como el eterboard. (Morales L., Antamba T. \& Cuaical F., 2017).

Para conseguir que los nuevos materiales y sistemas constructivos sean aplicados a edificaciones, estos primeramente deben cumplir con requisitos de resistencia, durabilidad, como también, al entrar en interacción con los sistemas estructurales, deben aportar a reducir la vulnerabilidad sísmica y mejorar la resiliencia de las estructuras. La inclusión de nuevos materiales, sistemas constructivos y criterios de análisis y diseño estructural, deben ser aquellos que se aproximen a los posibles eventos que puedan reflejar la realidad de nuestras edificaciones.

El costo de un nuevo sistema constructivo es superior al tradicional de hormigón armado, pero se pueden optimizar recursos dentro de los tiempos de ejecución de la obra y, además se alcanza un mejoramiento del comportamiento estructural de las edificaciones ante posibles desastres, esto para salvaguardar la integridad y la vida de seres humanos que debe ser la prioridad al momento de la construcción de una estructura.

Para el uso de los paneles como elementos estructurales se debe conocer las características de los paneles modulares M2, los sistemas de pisos con placas coo- perantes y la mampostería confinada:

- Los paneles modulares M2 se caracterizan por estar compuestos por planchas de poliestireno expandido corrugadas en una dirección, malla electro-soldada, conectores de acero y hormigón que, en conjunto trabajan como un sistema de piso unidireccional. (Morales L., Antamba T. \& Cuaical F., 2017).

- Las placas cooperantes o stell deck están conformadas por planchas preformadas hechas de acero estructural que se combinan con el hormigón, comportándose como un elemento estructural mixto hormigón-acero. (Morales L., Antamba T. \& Cuaical F., 2017).

Con lo expuesto anteriormente, el objetivo de la presente investigación es implementar paneles modulares M2 en los sistemas estructurales de edificaciones, cuyo fin es disminuir el peso de la edificación con respecto a la losa con placa cooperante o tradicional, así como también disminuir el peso de la mampostería, logrando reducir el peso total de la estructura y valores de cortante basal, derivas de piso y periodos de vibración, para obtener estructuras más estables y seguras. (Morales L., Antamba T. \& Cuaical F., 2017).

Para este propósito, es importante conocer las características físico - mecánicas de los sistemas de piso con panel modular M2, de la losa con placa cooperante (stell deck) y de la mampostería confinada con panel modular M2, para implementar en estructuras aporticadas de hormigón armado y acero estructural.

Para implementar los paneles M2 como sistema de piso, es necesario conocer el comportamiento estructural de los mismos y su interacción de manera conjunta a fin de determinar que su forma de trabajo como un elemento de entre piso es factible o no, para lo cual se deben efectuar modelaciones puntuales y por separado de las edificaciones. De la misma manera es importante determinar ¿cuál es la contribución de la mampostería con panel modular M2 a la rigidez lateral de las estructuras aporticadas?. (Morales L., Antamba T. \& Cuaical F., 2017).

Para verificar la implementación de los materiales antes indicados, se aplicaron en modelos estructurales de edificaciones existentes de 6 y 16 pisos implementadas los tipos de losas para obtener las respuestas estructurales máximas, resultado del comportamiento de dichas edificaciones, ante cargas actuantes laterales y gravitacionales. Estas edificaciones son regulares en planta y elevación.

En cambio, para incluir la mampostería con pales modulares M2 en sistemas aporticados se seleccionó, para el análisis, proyectos arquitectónicos destinados a uso residencial de 3, 6 y 9 pisos, en Hormigón Armado y Acero estructural, todos con una configuración geométrica regular en planta y elevación.

Finalmente, se debe comparar los modelos estructurales con sistemas de piso mediante paneles modulares M2 y placa cooperante, como también el sistema apor- 
ticado, con la inclusión de la mampostería con paneles modulares M2 y sin ella, para determinar las respuestas estructurales máximas y comparar los aspectos económicos y constructivos para cada caso de estudio. (Morales L., Manosalvas G., \& Tarapués J., 2017).

\section{Metodología}

En la presente investigación se analizará y comparará las respuestas estructurales máximas de una edificación residencial de 6 pisos y otra de oficinas de 16 pisos, que constan de un sistema estructural tradicional (columnas y vigas) de hormigón armado, en las cuales se implementan dos sistemas de piso, losas con tecnología M2 y losas con Placa Cooperante, que serán implantados dentro del Distrito Metropolitano de Quito, como se muestra en las figuras 1 y 2 de los anexos (formato digital). Asimismo, se incluirá la mampostería con pales modulares M2 en sistemas aporticados; para este fin se seleccionó para el análisis proyectos arquitectónicos destinados a viviendas de 3, 6 y 9 pisos, en Hormigón armado y estructura metálica, cuya área en planta es de $317.95 \mathrm{~m}^{2}, 390.58 \mathrm{~m}^{2}, 136.57 \mathrm{~m}^{2}$ respectivamente con una configuración geométrica regular en planta y elevación, implantados también dentro del Distrito Metropolitano de Quito como se muestra en la figura 3, figura 4, figura 5, figura, figura 7 y figura 8 de los anexos (Formato digital).

Además, se reunirá información para conocer las características que tienen los paneles de tecnología M2, y desarrollar varias hipótesis con las cuales iniciar el diseño e implementación de la losa en la estructura de hormigón.Se realiza el pre-diseño de los elementos estructurales de columnas, vigas y losas; para este último elemento se toma en cuenta las recomendaciones que hacen los fabricantes dentro de sus catálogos.

Se calcula el espectro de respuesta elástico e inelástico de aceleraciones del sismo de diseño bajo las recomendaciones que hace la Norma Ecuatoriana de la Construcción-Peligro Sísmico (NEC-SE-DS, NEC15).

Se realizarán modelaciones en programas computacionales estructurales, donde se ingresarán los datos de geometría de la edificación, las secciones obtenidas del pre-diseño de columnas y vigas, las características de los materiales, el espectro de respuesta inelástico, para obtener las respuestas estructurales de los análisis lineales estático y dinámico que nos permitan obtener resultados del comportamiento de los sistemas de piso. Para una mejor visualización de resultados se realizará cuadros comparativos de las respuestas estructurales máximas obtenidas del análisis, precios de los materiales que intervienen en la construcción de la obra gris, para cada estructura, con cada tipo de losa, además de las ventajas y desventajas que ofrecen estos sistemas de piso.

\section{Resultados panel modular M2 como losas}

Existe una reducción del $5.00 \%$ en el peso de la edificación de 6 pisos, al reemplazar la losa de placa colabo- rante por la losa de tecnología M2. (Morales L., Antamba T. \& Cuaical F., 2017).

De igual forma en la edificación de 16 pisos con un porcentaje de reducción del 2.06\%. (Morales L., Antamba T. \& Cuaical F., 2017).

La reducción del peso en la edificación de 6 pisos influyo en todas las respuestas estructurales analizadas donde cuyos porcentajes de reducción son;

Periodo de vibración: $2.79 \%$

- Cortante Basal: $5.26 \%$

- Deriva inelástica máxima de piso: 4.89\%

(Morales L., Antamba T. \& Cuaical F., 2017).

De igual manera en las respuestas estructurales de la edificación de 16 pisos, los porcentajes de reducción obtenidos son:

- Periodo de vibración: 2.27\%

- Cortante Basal: 4.44\%

- Deriva inelástica máxima de piso: 4.09\%.

(Morales L., Antamba T. \& Cuaical F., 2017).

Ver en anexos las figuras de la 9 a la 24

(Formato digital).

Comparación metros cuadrados de construcción

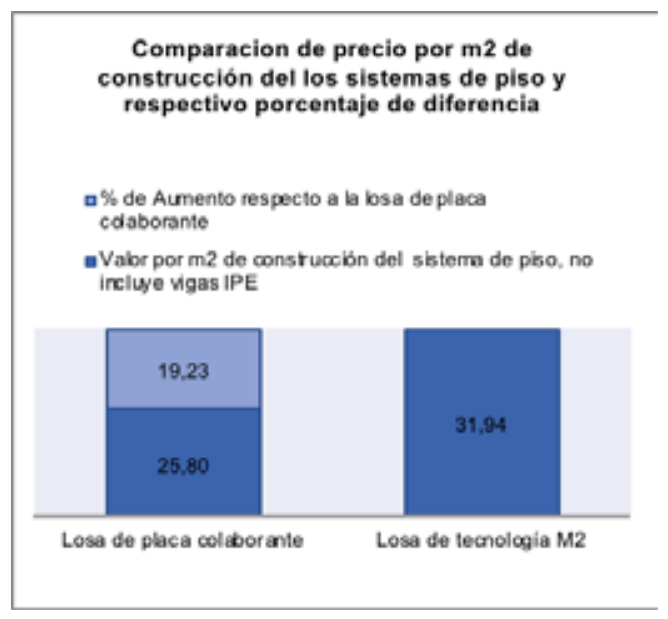

Figura 1. Comparación de $\mathrm{m} 2$ de construcción de sistema de piso. (Morales L., Antamba T. \& Cuaical F., 2017).

El costo por metro cuadrado de materiales en la Iosa de placa colaborante es de 25.80 USD. y 31.94 USD. de losa de tecnología M2, generando una diferencia de $19.23 \%$ en su costo.

\section{Panel modular M2 como mampostería confinada Edificios de hormigón armado Comparación de Cortante Basal}

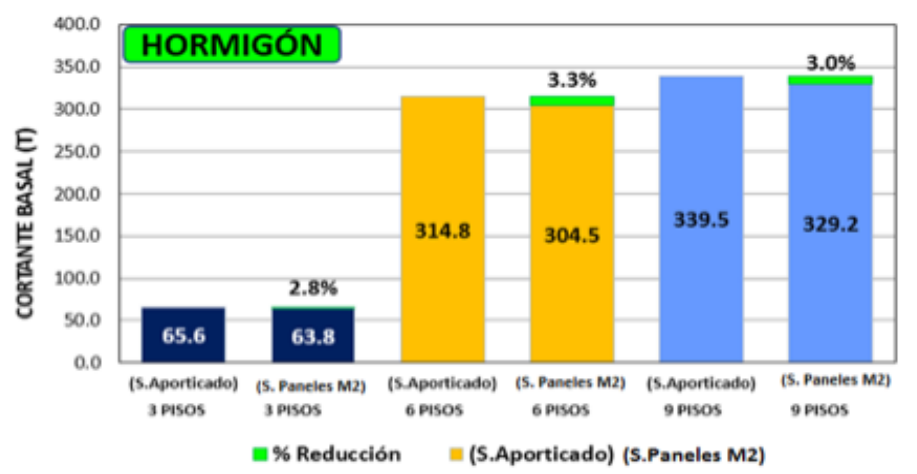

Figura 2. Cortante Basal de las edificaciones aporticadas y con mampostería. 


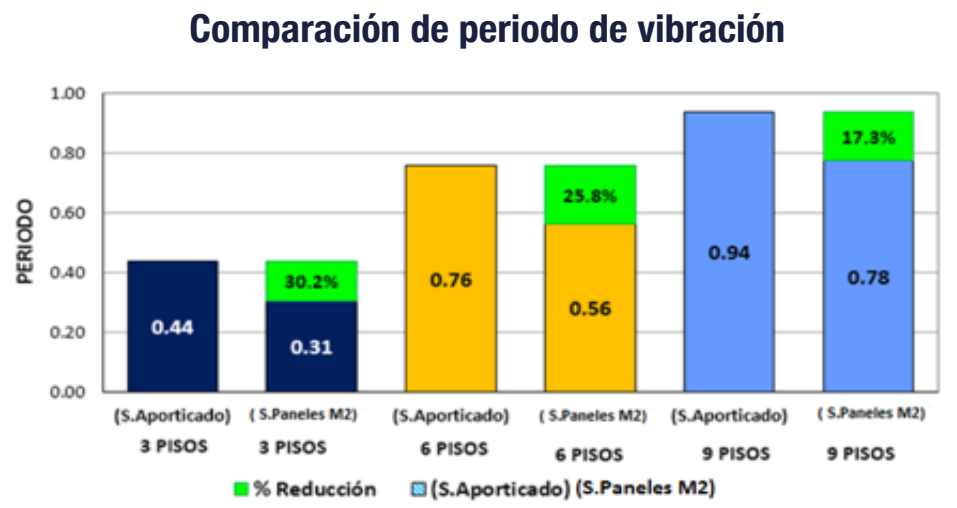

Figura 3. Periodo de las edificaciones aporticadas y con mampostería. (Morales L., Manosalvas G. \& Tarapués J., 2017)

\section{Comparación de derivas}

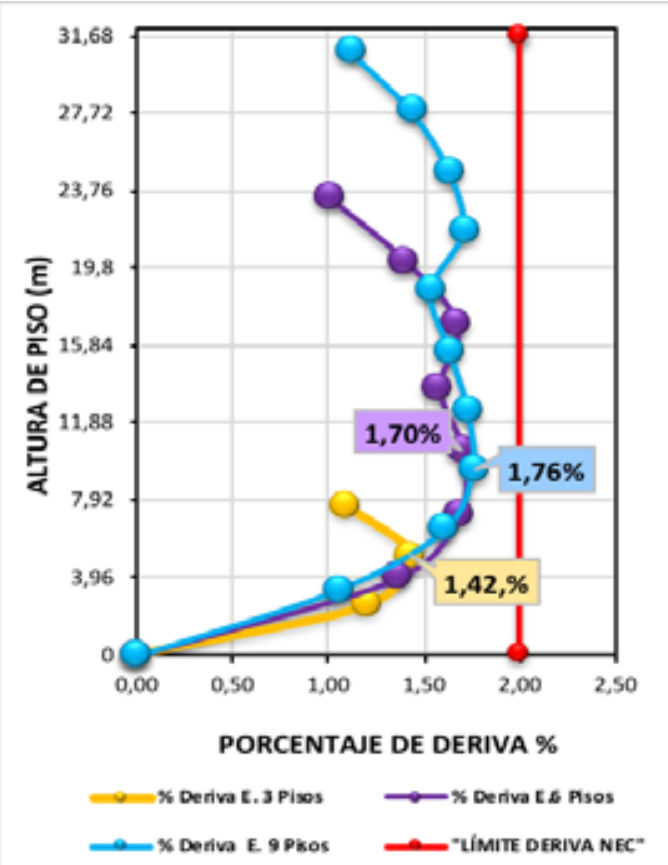

Figura 4. Derivas de piso. "Análisis Dinámico" Sistema Aporticado (Morales L., Manosalvas G., \& Tarapués J., 2017).

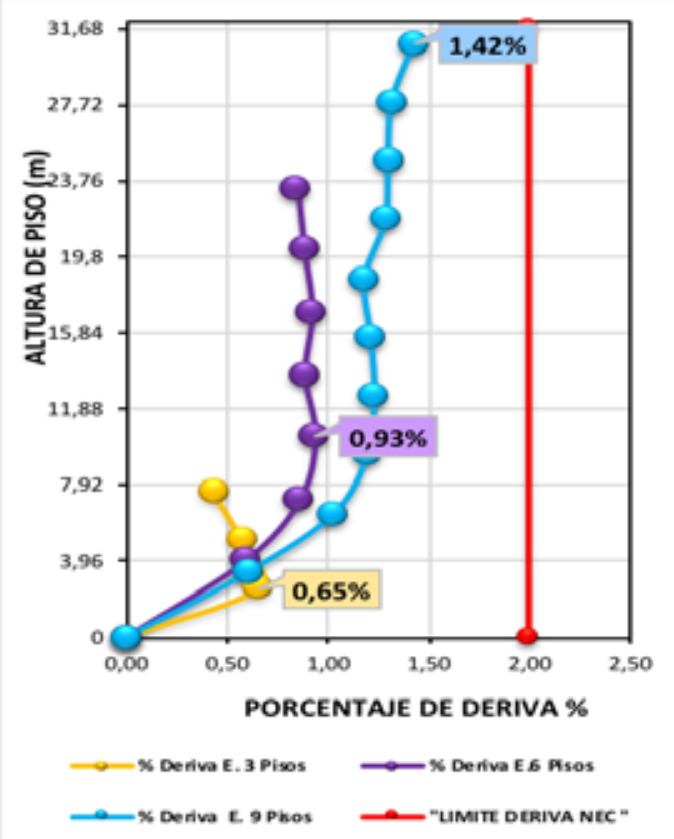

Figura 5. Derivas de piso. "Análisis Dinámico" Sistema Aporticado con paneles modulares M2 (Morales L., Manosalvas G., \& Tarapués J., 2017).Da doluptat
Edificios de acero

\section{Comparación de cortante basal}

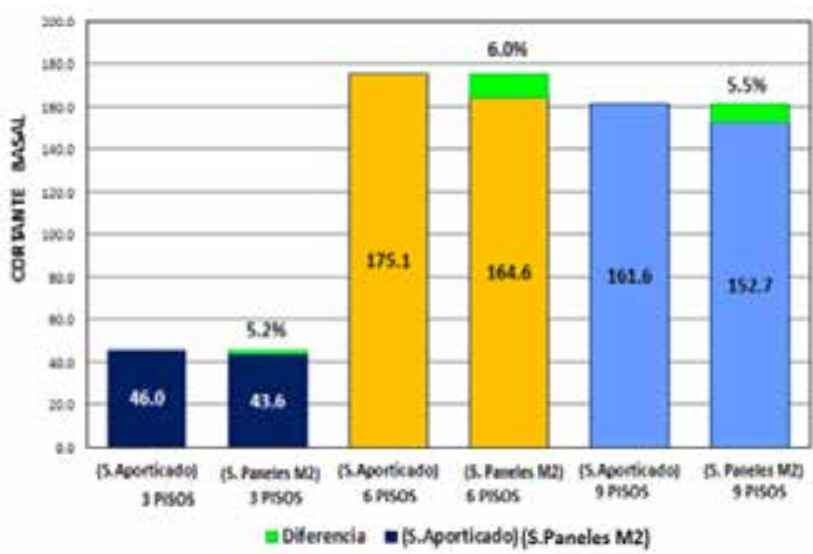

Figura 6. Cortante Basal de las edificaciones aporticadas y con mampostería. (Morales L., Manosalvas, G., \& Tarapués, J., 2017)

\section{Comparación de periodo de vibración}

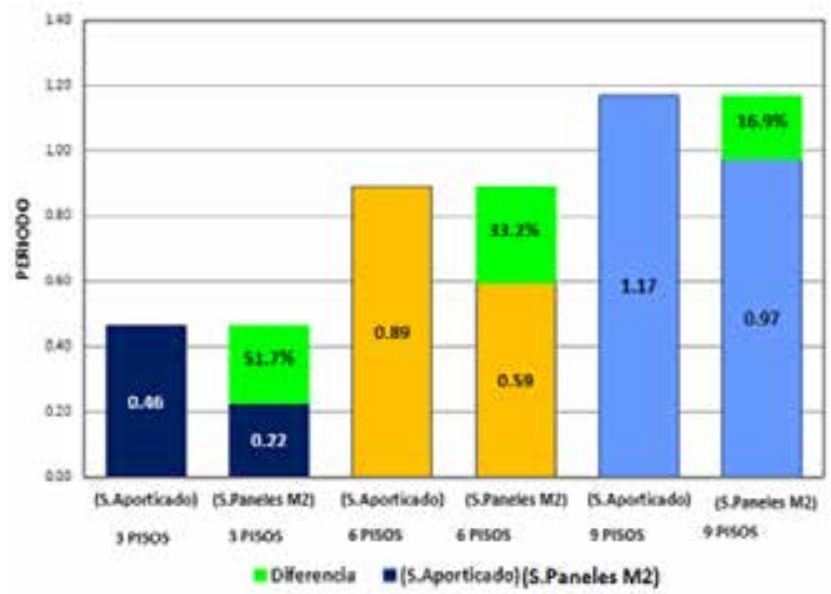

Figura 7. Periodo de las edificaciones aporticadas y con mampostería. (Morales L., Manosalvas G., \& Tarapués J., 2017)

\section{Comparación de Derivas}
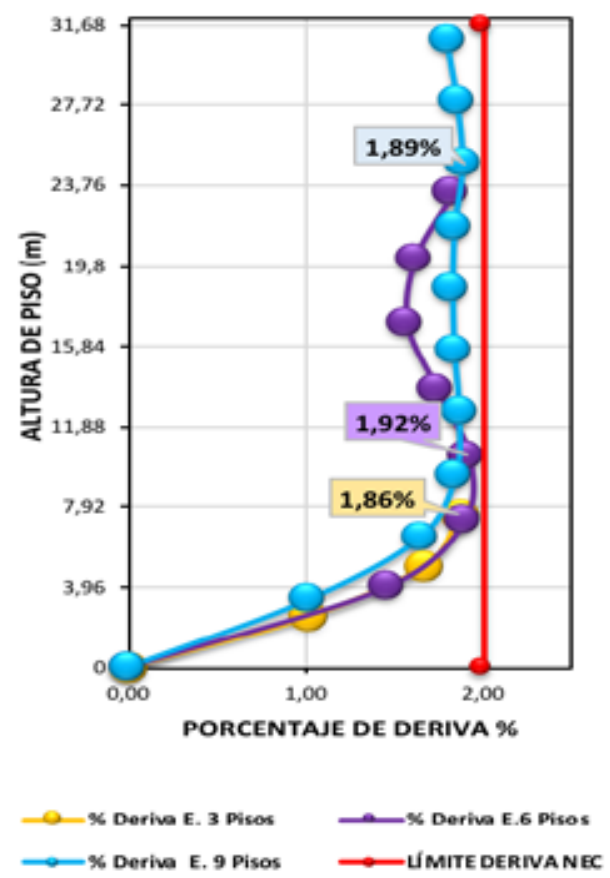

Figura 8. Derivas de piso. "Análisis Dinámico" Sistema Aporticado (Morales L., Manosalvas G., \& Tarapués J., 2017) 

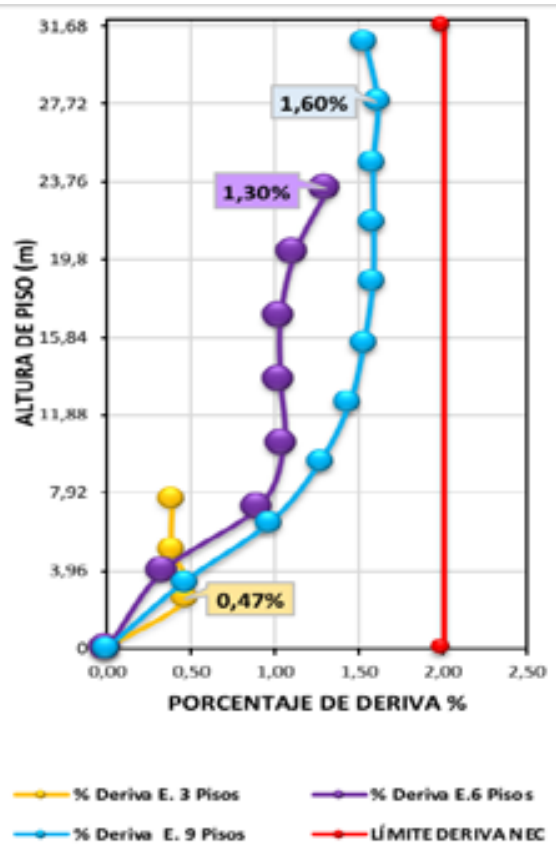

Figura 9. Derivas de piso. "Análisis Dinámico" Sistema Aporticado con paneles modulares M2 (Morales L., Manosalvas G., \& Tarapués J., 2017)

\section{Comparación entre edificios de hormigón y acero}

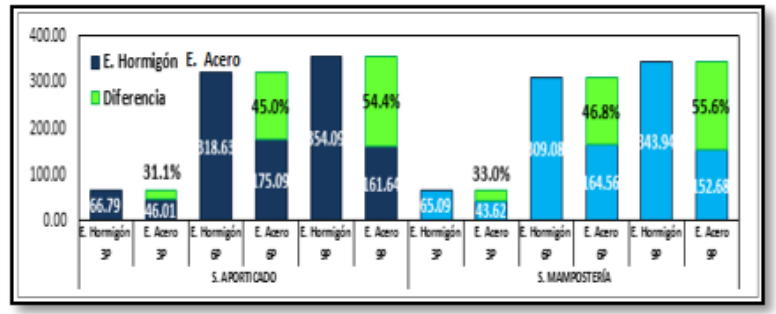

Figura 10. Cortante Basal de las edificaciones aporticadas y con mampostería. (Morales L, Manosalvas G., \& Tarapués J., 2017)

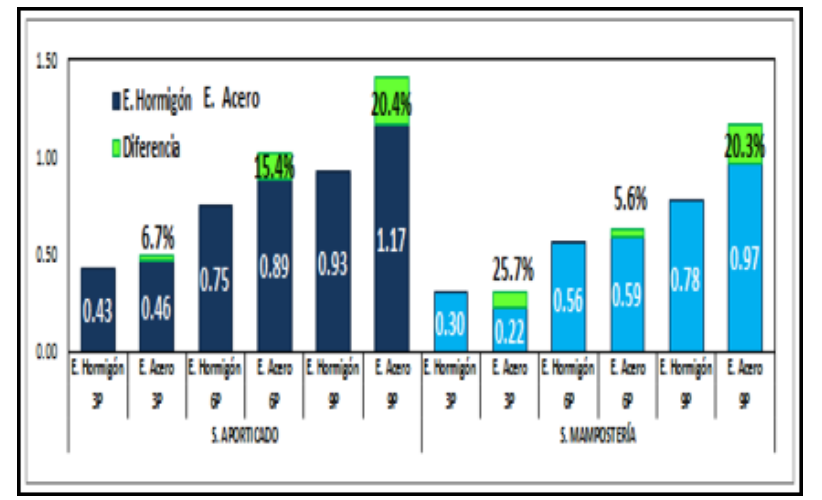

Figura 11. Periodo de las edificaciones aporticadas y con mampostería. (Morales Luis, Manosalvas G., \& Tarapués J., 2017)

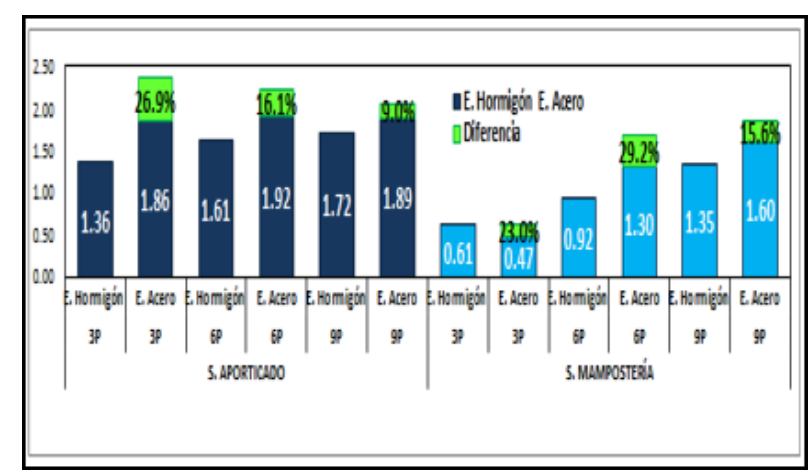

Figura 12. Derivas de Piso de las edificaciones aporticadas y con mampostería. (Morales Luis, Manosalvas G., \& Tarapués J., 2017)

\section{Conclusiones}

La inclusión de la mampostería (M2) dentro del sistemas estructurales aporticado, disminuye la vulnerabilidad estructural y mejora la resiliencia ante la acción sísmica.

Las derivas de piso disminuyen al incluir la mampostería M2 dentro del análisis estructural, por el aumento de rigidez lateral que aporta el M2 al sistema estructural aporticado.

El porcentaje de reducción obtenido en peso, cortante y periodo de vibración de las estructuras de acero fue de un 5\% - $10 \%$ más que en las estructuras de hormigón.

La disminución del periodo fundamental de vibración de las edificaciones de hormigón armado como de acero estructural, es resultado de la inclusión de la mampostería M2 dentro del sistema aporticado.

La mampostería M2 es factible usarlas en todo tipo de edificaciones, mejorando el comportamiento global de los sistemas aporticados y disminuyendo el costo y tiempo de ejecución en obra, en comparación con un sistema tradicional.

Para certificar las bondades que se obtiene al incluir los paneles M2 como mampostería dentro del sistema estructural aporticado, estos deben arriostrarse al marco estructural de hormigón armado y acero estructural, mediante el anclaje a varillas de refuerzo horizontales y verticales (chicotes) previamente dispuestas en el marco estructural.

La reducción de peso entre la Losa con Placa Colaborante y la Losa con Paneles de Tecnología M2 se debe a que el núcleo de poliestireno está compuesto por un $98 \%$ de aire siendo un elemento muy ligero.

Para evitar deflexiones que sobrepasen la máxima admisible, en la losa con Tecnología M2, es necesario integrar vigas IPE al sistema de entrepiso entre las vigas principales de hormigón armado, reduciendo así, considerablemente las deflexiones.

La variación en el porcentaje reducción del peso de las edificaciones, está en función del empleo de vigas secundarias IPE con mayor peralte, para disminuir la vibración que generaba al implementarse la losa de tecnología M2 en grandes luces que se presentaba en la edificación de 16 pisos con tramos de $6.85 \mathrm{~m}$, diferente a la edificación de 6 pisos que comprendían tramos entre 3 y $5.40 \mathrm{~m}$, conservando en todos los tableros el mismo peralte de las vigas IPE utilizado para la losa de placa colaborante. 
El índice de flexibilidad presente en un sistema de piso, sugiere que; la rigidez del mismo aumenta conforme la altura de la edificación y con la relación a la configuración de la estructura; además es un factor significativo en la determinación de la respuesta sísmica ya que interviene en los resultados de deformaciones y derivas.

Al cambiar el sistema de losa de Placa Colaborante a Paneles de tecnología M2 la estructura tuvo cambios en sus elementos, como en vigas y columnas, donde se redujeron los valores de momento y cortante, debido a la reducción de peso de la estructura y aumentaron las deflexiones en vigas, por las características resistentes del material.

Al reemplazar la losa de placa colaborante por la losa de tecnología M2, en el sistema estructural tradicional de hormigón armado se consiguió mayor rigidez y estabilidad a las edificaciones ante un evento sísmico.

A fin de garantizar los resultados obtenidos en esta investigación al implementar los paneles modulares M2 como sistemas de piso (losas), estas deben estar conectadas a vigas secundarias de acero estructural, a través de conectores de corte tipo stud o similar, formando una sección compuesta.

A pesar de que la reducción del peso total del edificio de 6 pisos fue mayor al edificio de 16 pisos, los porcentajes de reducción, en las respuestas estructurales de las edificaciones son similares, a causa de que las edificaciones de gran altura son más sensibles ante la variación de su masa, presentando así un mejor comportamiento al reducir el peso de sus losas.

El costo total de los materiales que intervienen en la construcción de las edificaciones de 6 y 16 pisos implementando el sistema de losa de tecnología $\mathrm{M} 2$, resulta un $12.96 \%$ más costoso con respecto a las edificaciones implementadas losa de placa colaborante ya que, a pesar de la disminución de las secciones de columnas y vigas, estas no son tan significativas como para reducir costos en lo que es la obra gris de la estructura.

Además del incremento en el costo de obra de las edificaciones, el sistema constructivo de la losa con paneles de tecnología M2 en comparación con el sistema constructivo de placa colaborante, es menos eficiente, ya que requiere más tiempo de ejecución, debido a la necesidad de más procedimientos técnicos en obra, convirtiéndose en un proyecto más caro y menos viable.

\section{Referencias bibliográficas}

Antamba, T\&Cuaical, F. (2017). Análisis comparativo del comportamiento estructural de una edificación de 6 y 16 pisos implementando losas con paneles de tecnología M2 frente a losas con placa cooperante. http://www.dspace.uce. edu.ec/bitstream/25000/14260/1/T-UCE-0011IC327-2018.pdf

Manosalvas, G. \& Tarapués, J. (2017). Análisis comparativo de las derivas de piso, para edificaciones de 3, 6 y 9 pisos entre un sistema de muros confinados con M2 y un sistema aporticado. http://www.dspace.uce.edu.ec/handle/25000/13272

ACl 318S-14. (2015). Requisitos de Reglamento para Concreto Estructural (Versión en español y en Sistema Métrico SI). Recuperado de https://civilshare.files.wordpress.com/2016/07/ aci_318s_14_en_espanol.pdf

Aguiar, R. (2016). Análisis Sísmico por Desempeño. Recuperado de https://www.researchgate. net/publication/280627456_Analisis_Sismico_ por_Desempeno

M2 EMMEDUE. (2014). Manual Técnico "Sistema Constructivo Emmedue". Recuperado de https:// issuu.com/gruppoprandi/docs/emmedue_spa.

Norma ecuatoriana de la construcción NEC. Capítulo NEC-SE-HM. Estructuras de hormigón armado.

Norma ecuatoriana de la construcción NEC. Capítulo NEC-SE-DS. Cargas sísmicas diseño sismo resistente.

Norma ecuatoriana de la construcción NEC. Capítulo NEC-SE-PS. Peligro sísmico.

PANECONS. (2012). Proceso Descriptivo para Cálculo Estructural con el Sistema Hormi2 Dirigido a Ingenieros Estructurales y Calculistas.

Recuperado de https://es.scribd.com/presentation/98250118/Calculo-Hormi2-General. 


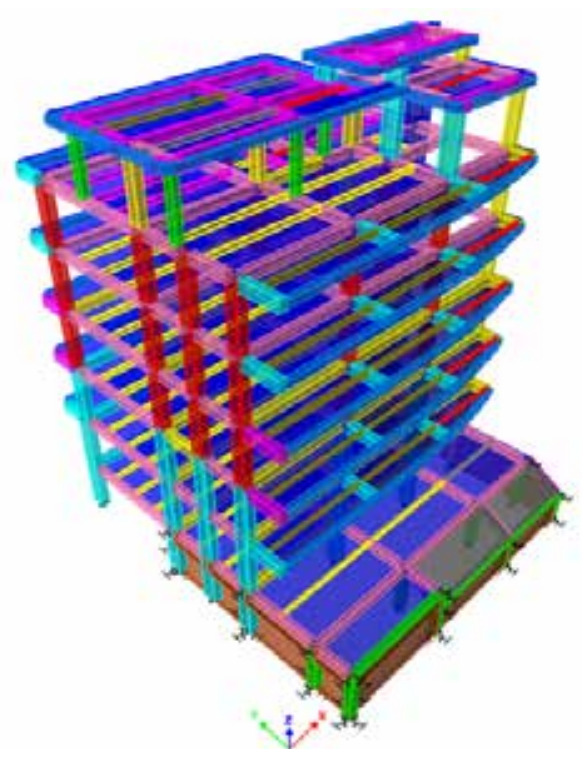

Figura 1. Sistema aporticado de hormigón armado. Edificio de 6 pisos. (Los autores)

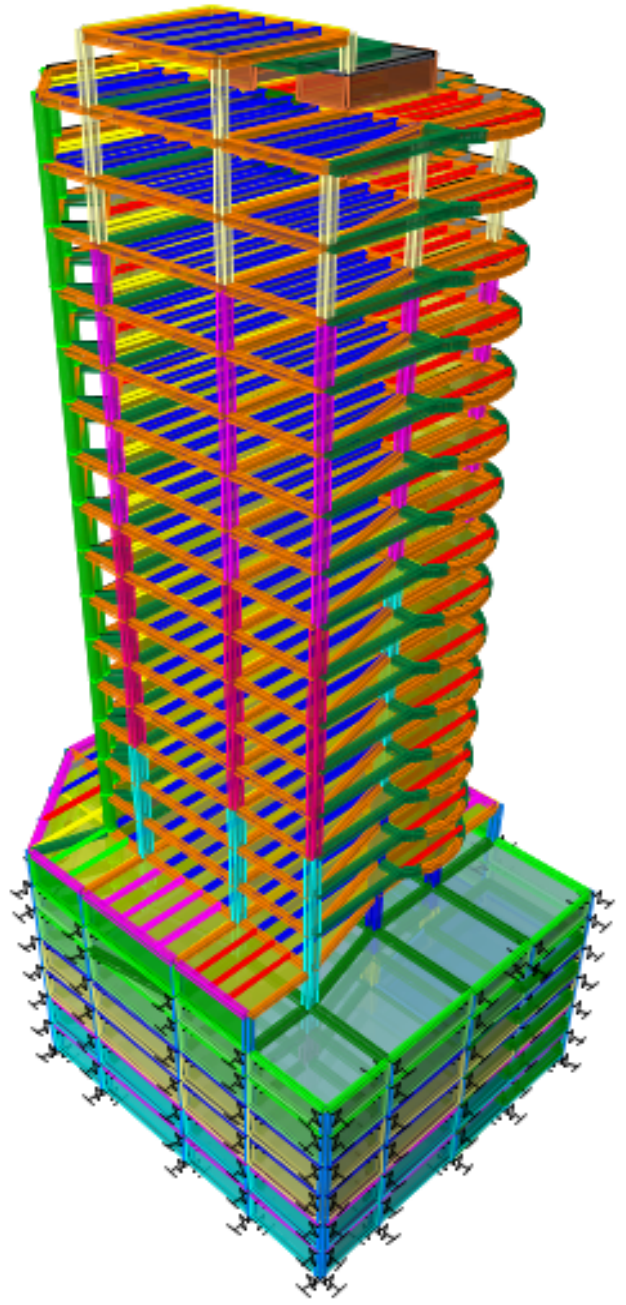

Figura 2. Sistema aporticado de hormigón armado. Edificio de 16 pisos. (Los autores)

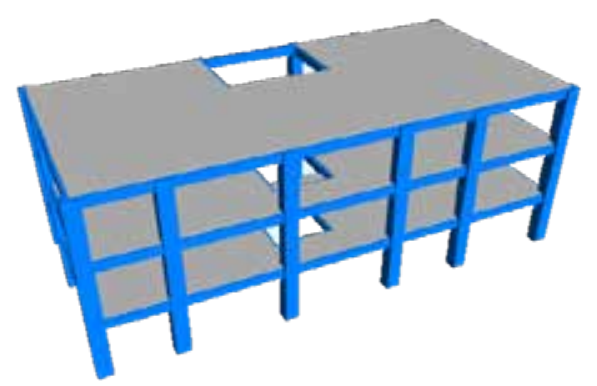

Figura 3. Sistema aporticado de hormigón armado. Edificio de 3 pisos. (Los autores)

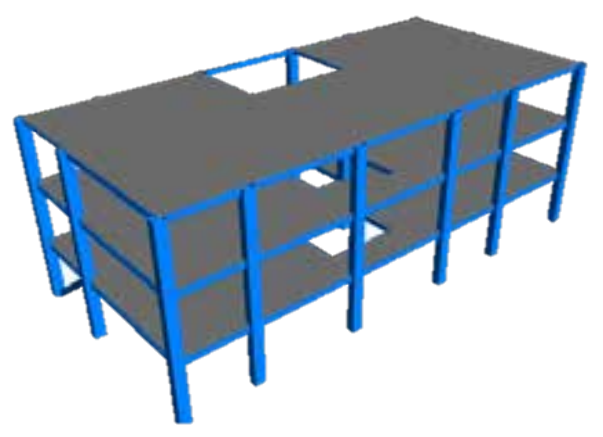

Figura 4. Sistema aporticado en acero estructural. Edificio de 3 pisos. (Los autores)

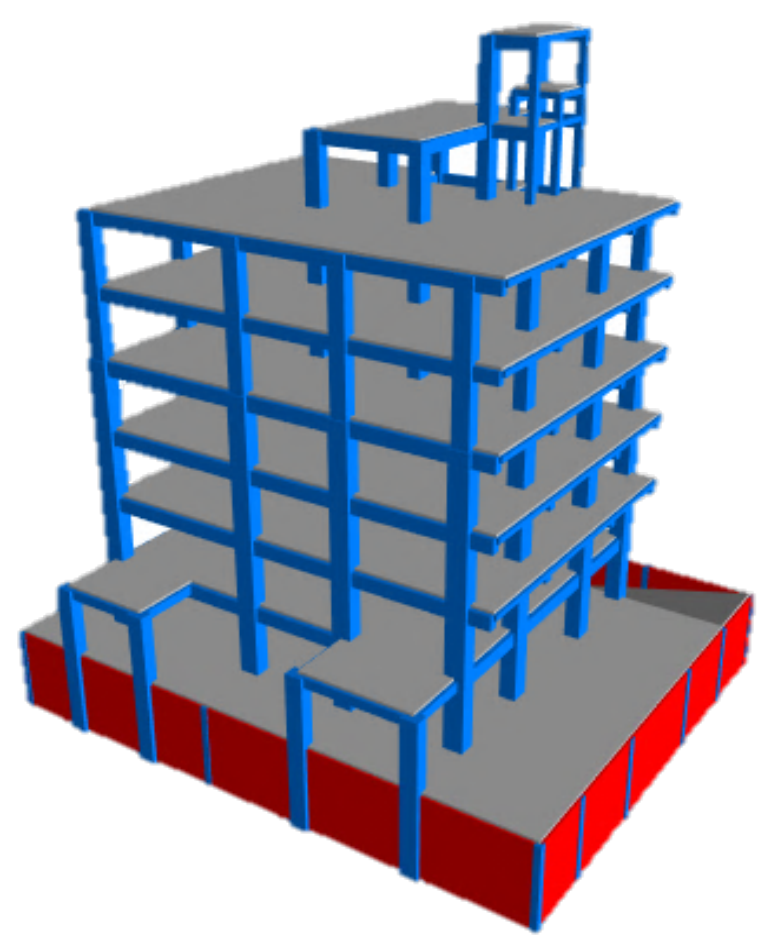

Figura 5. Sistema aporticado de hormigón armado. Edificio de 6 pisos. (Los autores) 
Comparacion de Peso Total, Edificio de 16 pisos

$\square$ Peso (Ton) $\quad$ \% de Reducción

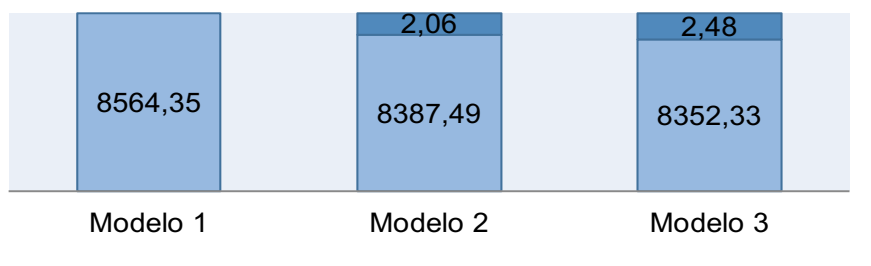

Figura 10. Comparación de pesos - Edificio de 16 pisos. (Morales L., Antamba T. \& Cuaical F. (2017)).

\section{Comparación de periodos de vibración}

\section{Comparacion de Periodo de Vibración Fundamental, Edificio de 6 pisos}

$\square$ Periodo de Vibración Fundamental (sec) $\square \%$ de Reducción

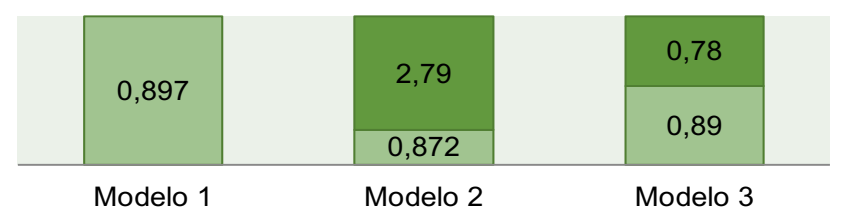

Figura 11. Comparación periodo de vibración fundamental, Edificio de 6 pisos. (Morales L., Antamba T. \& Cuaical F. (2017)).

\section{Comparacion de Periodo de Vibración Fundamental, Edificio de 16 pisos}

$\square$ Periodo de Vibración Fundamental (sec) $\square \%$ de Reducción

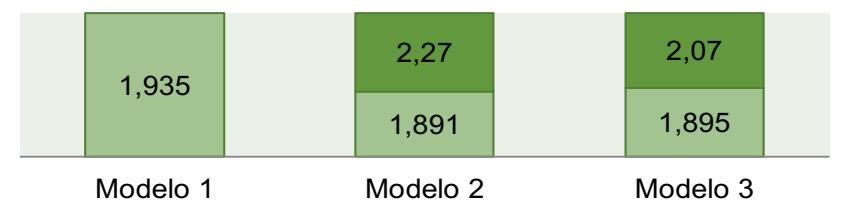

Figura 12. Comparación periodo de vibración fundamental, Edificio de 16 pisos. (Morales L., Antamba T. \& Cuaical F. (2017)).

\section{Comparación de cortante basal}

\section{Comparación del Cortante Basal Total, Edificio de 6 pisos}

$\square$ Cortante Basal Total en la base (ton) $\square \%$ de Reducción

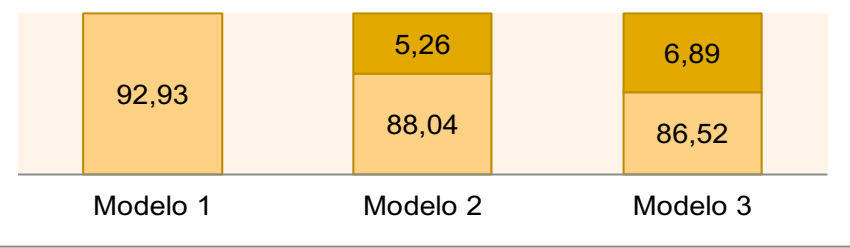

Figura 13. Comparación del Cortante Basal - Edificio de 6 pisos. (Morales L., Antamba T. \& Cuaical F. (2017)).
Comparación del Cortante Basal Total, Edificio de 16 pisos

$\square$ Cortante Basal Total en la base (ton) $\square \%$ de Reducción

\begin{tabular}{|l|c|c|}
\hline \multirow{2}{*}{207,28} & 4,44 & 5,07 \\
& 198,07 & 196,77 \\
\hline Modelo 1 & Modelo 2 & Modelo 3
\end{tabular}

Figura 14. Comparación del Cortante Basal - Edificio de 16 pisos. (Morales L., Antamba T. \& Cuaical F. (2017)).

\section{Comparación de derivas de piso}

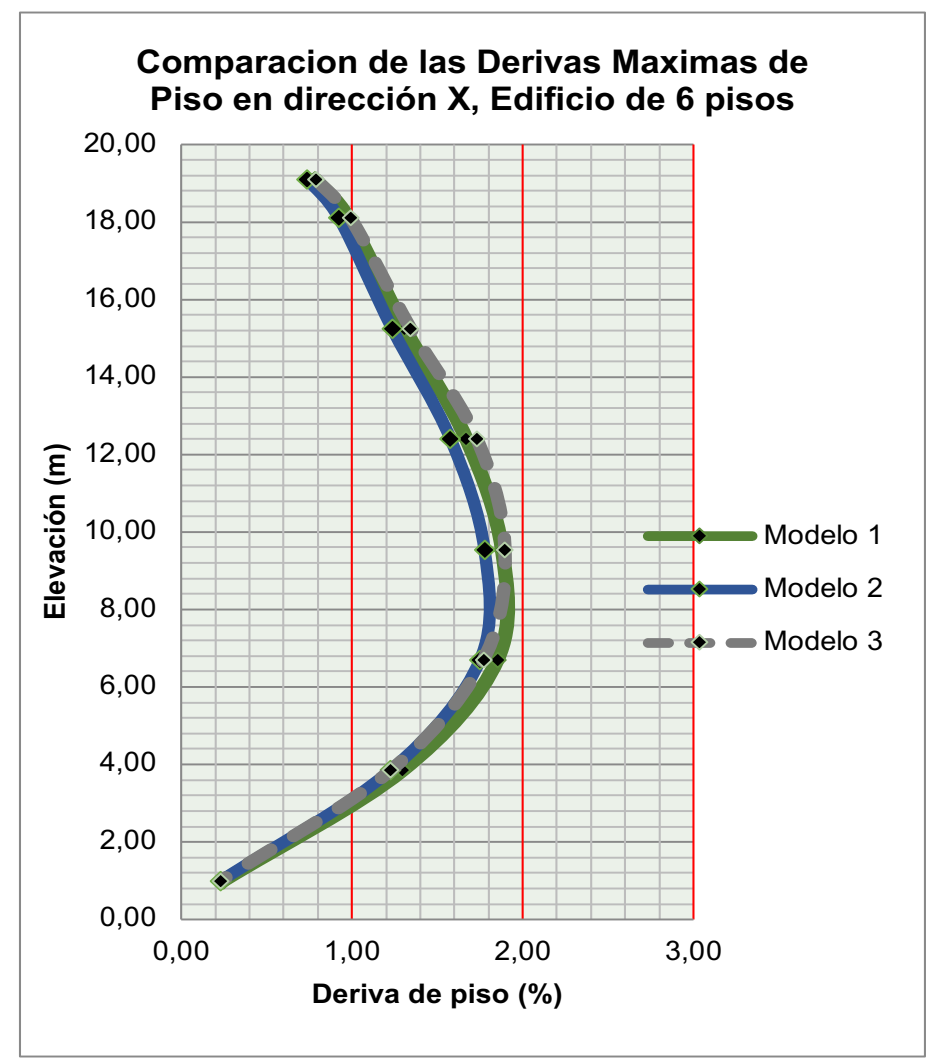

Figura 15. Comparación de Derivas de piso en la dirección X "Análisis Estático" - Edificio de 6 pisos. (Morales L., Antamba T. \& Cuaical F. (2017)). 
Comparacion de las Derivas Maximas de

Piso en dirección $Y$, dificio de 6 pisos

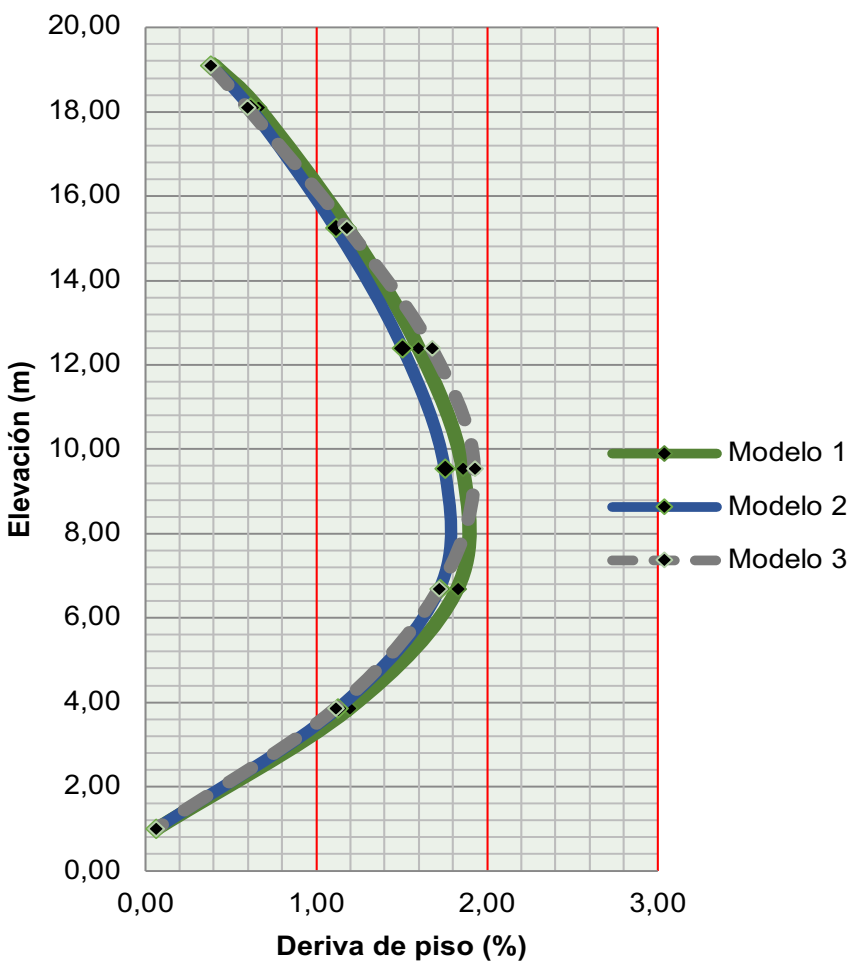

Figura 16. Comparación de Derivas de piso en la dirección $Y$ "Análisis Estático" - Edificio de 6 pisos. (Morales L., Antamba T. \& Cuaical F. (2017)).

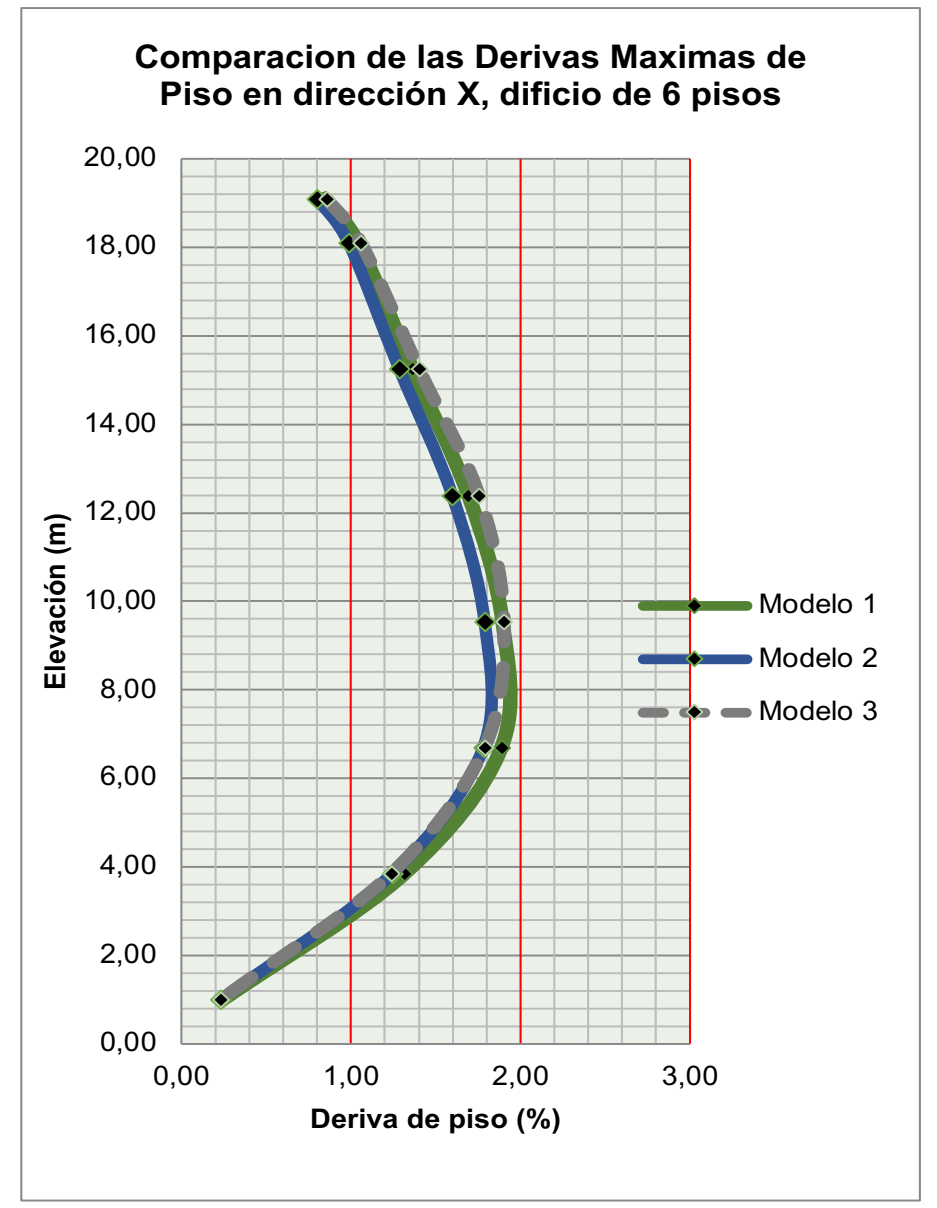

Figura 17. Comparación de Derivas de piso en la dirección X "Análisis Dinámico" - Edificio de 6 pisos. (Morales L., Antamba T. \& Cuaical F. (2017)).
Comparacion de las Derivas Maximas de Piso en dirección $Y$, dificio de 6 pisos

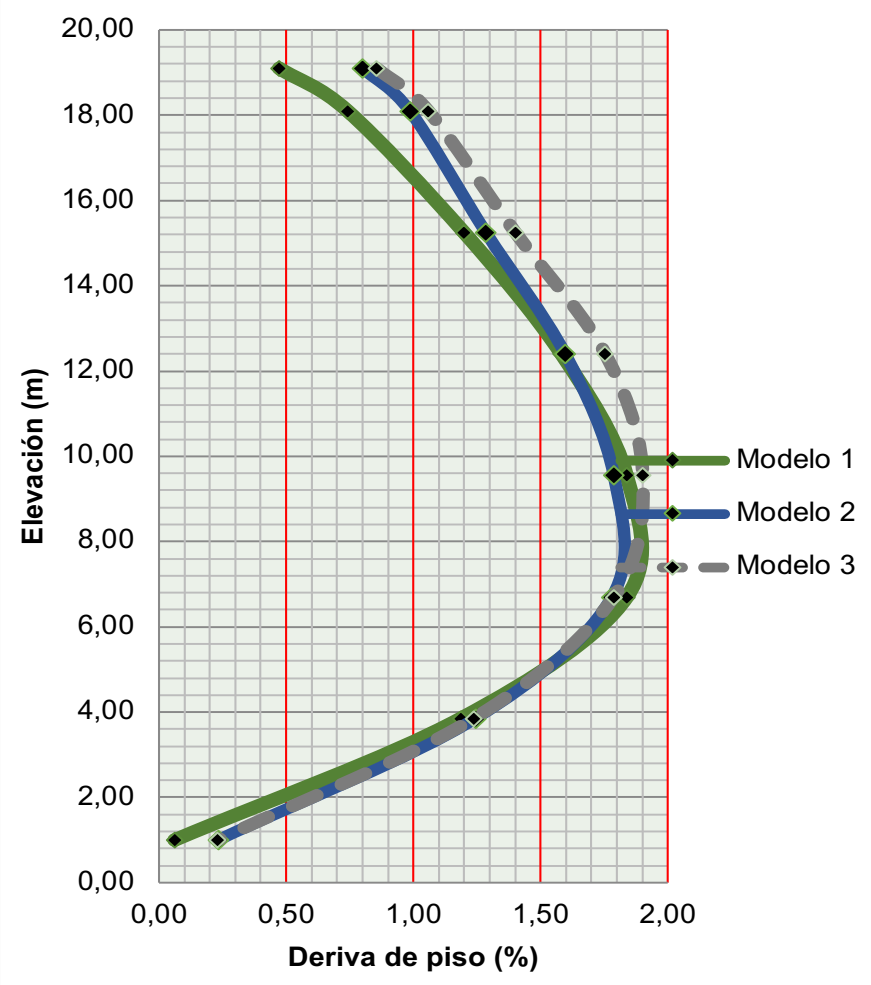

Figura 18. Comparación de Derivas de piso en la dirección $Y$ "Análisis Dinámico" - Edificio de 6 pisos. (Morales L., Antamba T. \& Cuaical F. (2017)).

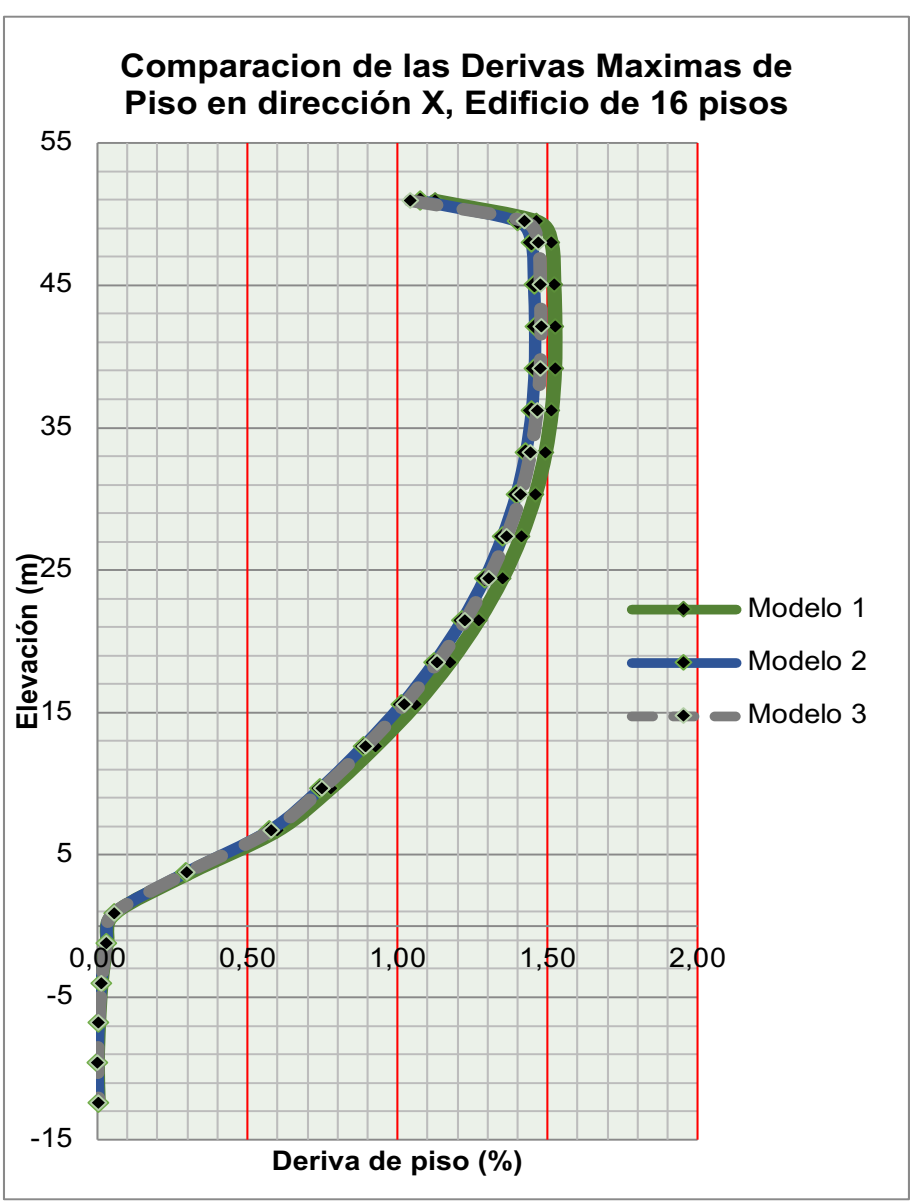

Figura 19. Comparación de Derivas de piso en la dirección X "Análisis Estático" - Edificio de 16 pisos. (Morales L., Antamba T. \& Cuaical F. (2017)). 


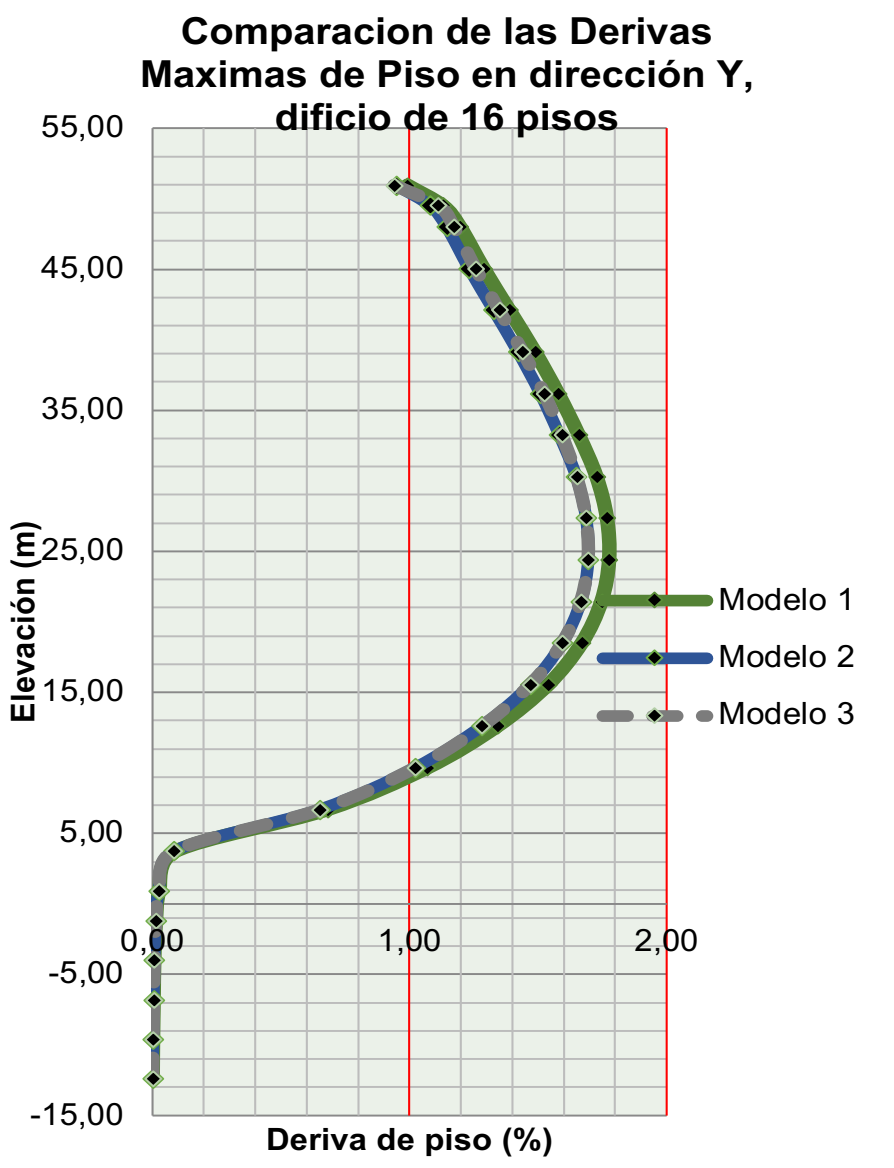

Figura 20.Comparación de Derivas de piso en la dirección $Y$ "Análisis Estático" - Edificio de 16 pisos. (Morales L., Antamba T. \& Cuaical F. (2017)).

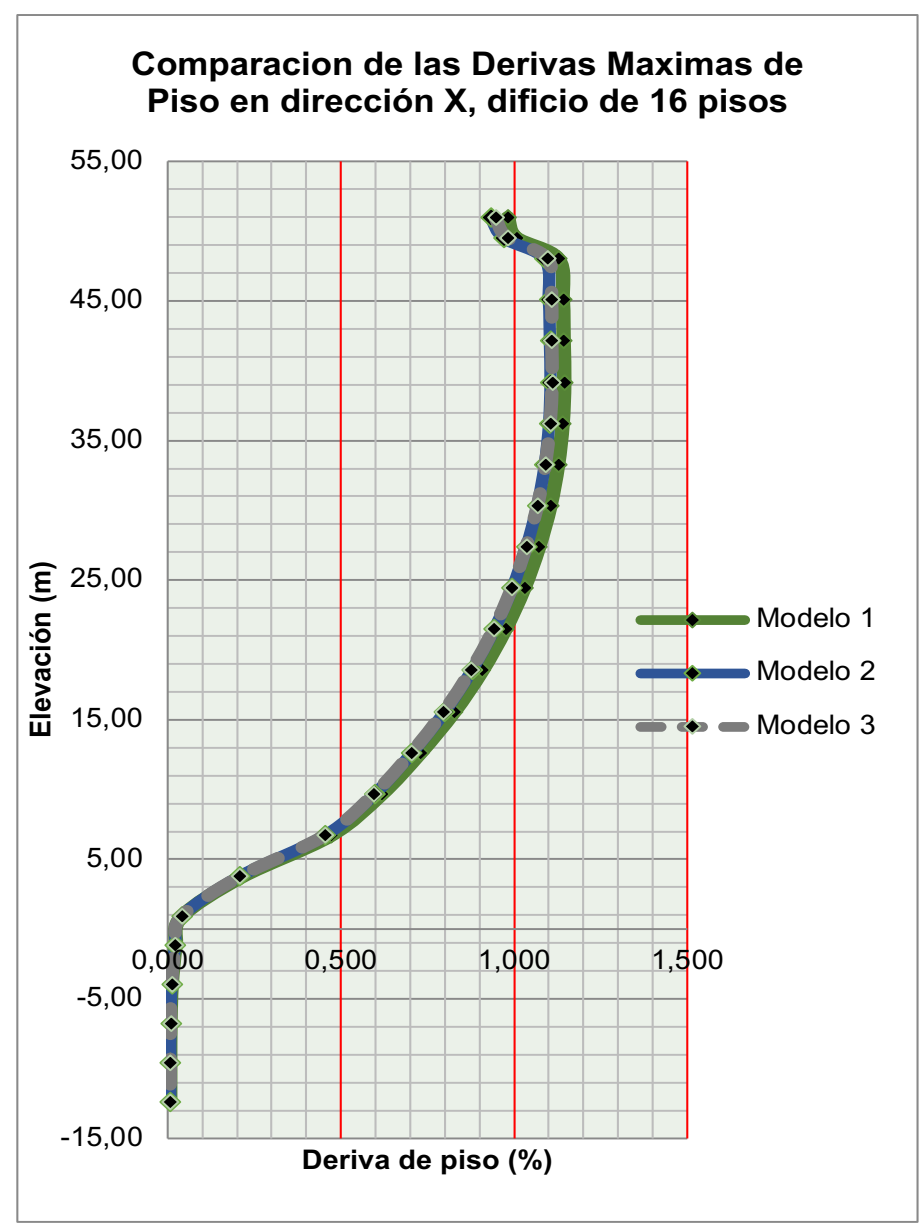

Figura 21. Comparación de Derivas de piso en la dirección X "Análisis Dinámico" - Edificio de 16 pisos. (Morales L., Antamba T. \& Cuaical F. (2017)).
Comparacion de las Derivas Maximas de Piso en dirección $\mathrm{Y}$, dificio de 16 pisos

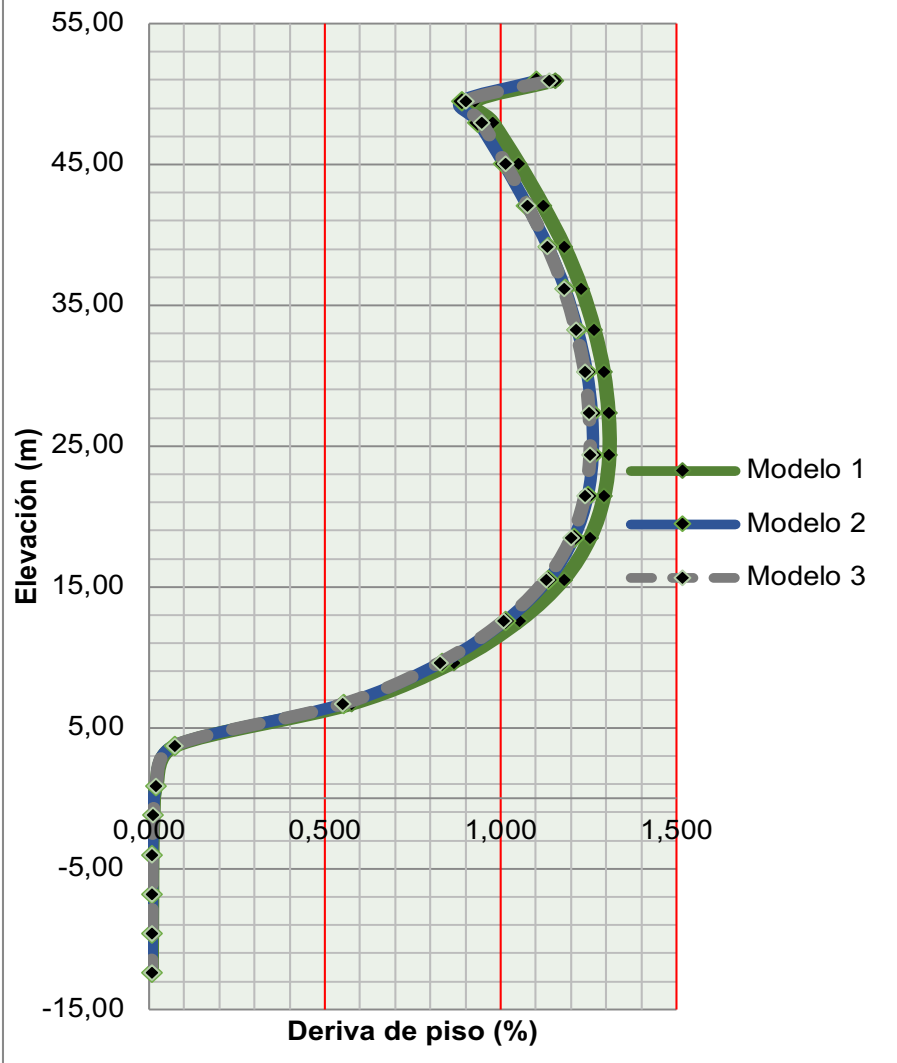

Figura 22. Comparación de Derivas de piso en la dirección $Y$ "Análisis Dinámico" - Edificio de 16 pisos. (Morales L., Antamba T. \& Cuaical F. (2017)).

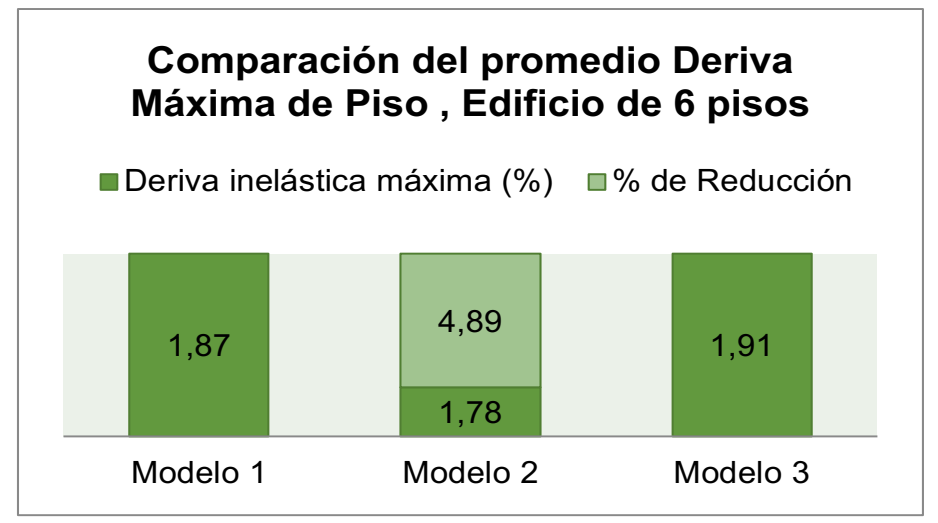

Figura 23. Porcentaje de disminución de derivas inelásticas en el Edificio de 6 pisos. (Morales L., Antamba T. \& Cuaical F. (2017)).

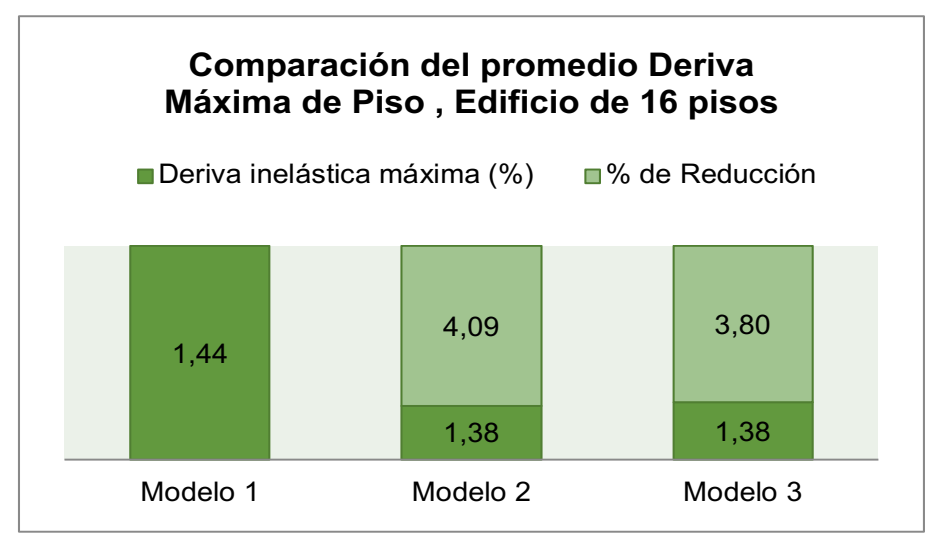

Figura 24. Porcentaje de disminución de la deriva inelástica en el Edificio de 16 pisos. (Morales L., Antamba T. \& Cuaical F. (2017)). 


\section{Conclusiones}

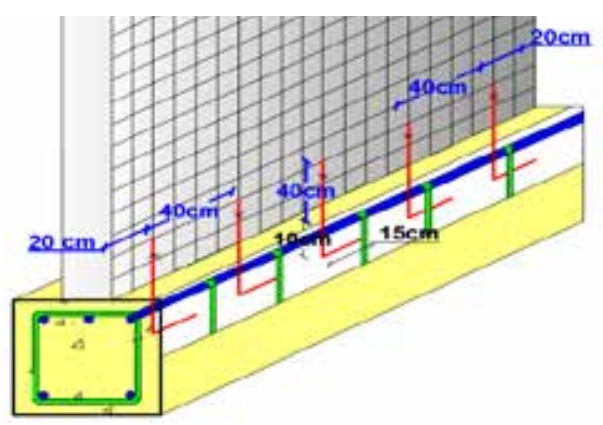

Figura 25. Detalle de anclaje de panel modular M2 como mampostería a viga de Hormigón armado. (Morales Luis, Manosalvas G., \& Tarapués J. (2017))

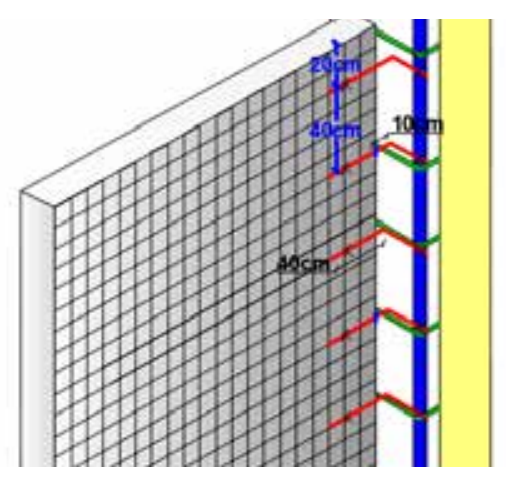

Figura 26. Detalle de anclaje de panel modular M2 como mampostería a columna de Hormigón armado. (Morales Luis, Manosalvas G., \& Tarapués J. (2017))

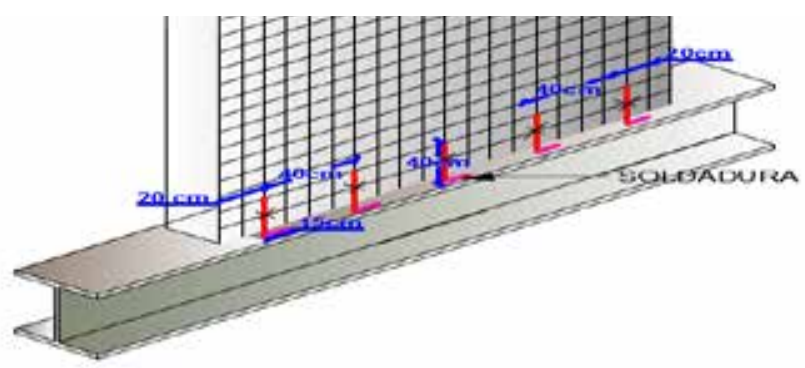

Figura 27. Detalle de anclaje de panel modular M2 como mampostería a viga de acero estructural. (Morales Luis, Manosalvas G., \& Tarapués J. (2017))

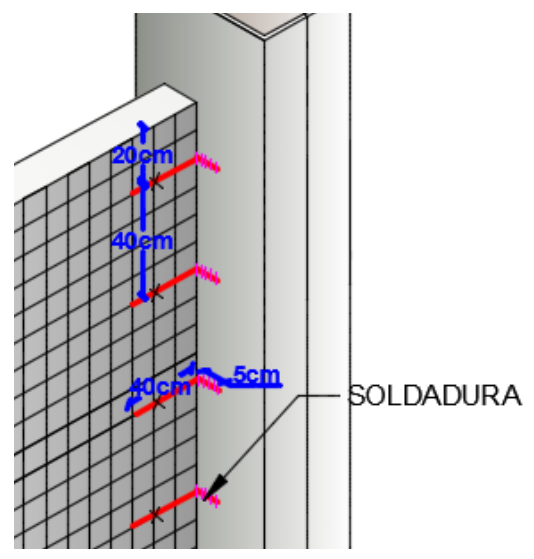

Figura 28. Detalle de anclaje de panel modular M2 como mampostería a columna de acero estructural. (Morales Luis, Manosalvas G., \& Tarapués J. (2017))

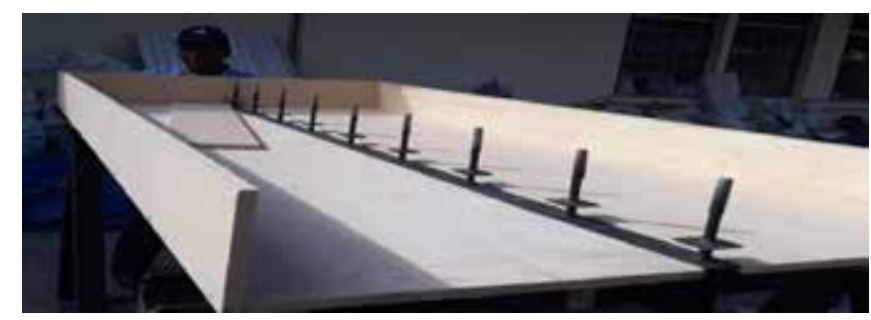

Figura 29. Conectores de corte en losas con panel modular M2. (Morales Luis, Guamán D. (2018))

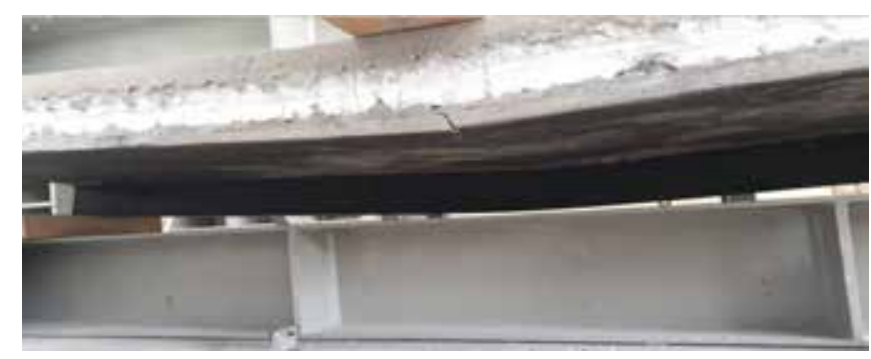

Figura 30. Ensayo a flexión de losa con panel modular M2. Sección compuesta de losa (Morales Luis, Guamán D. (2018)) 